\title{
Campylobacter rectus Infection Leads to Lung Abscess: A Case Report and Literature Review
}

\author{
Xiaohui Zhu,' Shijie Yu,' \\ Qiankuan Kang,' Yansen Qiu, ' \\ Mi Tian, ${ }^{2}$ Ehong Cao' \\ 'Department of Respiratory Medicine, \\ Nanjing Tongren Hospital, School of \\ Medicine, Southeast University, Nanjing, \\ Jiangsu, People's Republic of China; \\ ${ }^{2}$ Department of Respiratory Medicine, The \\ Affiliated Drum Tower Hospital of Nanjing \\ University Medical School, Nanjing, Jiangsu, \\ People's Republic of China
}

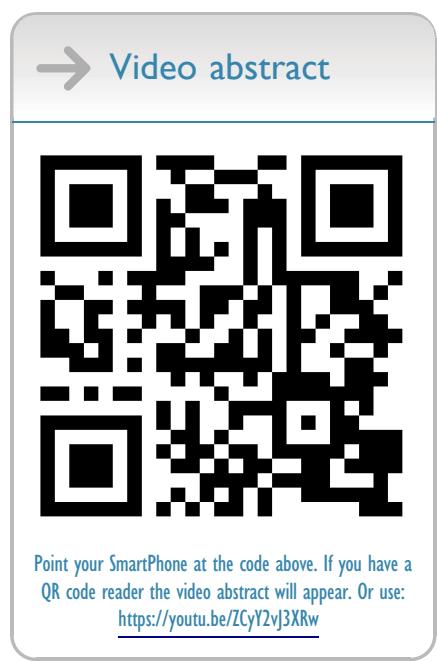

Correspondence: Ehong Cao

Department of Respiratory Medicine, Nanjing Tongren Hospital, School of Medicine, Southeast University, 2007 JiYin Road, Nanjing, 2 I I 102, Jiangsu, People's

Republic of China

Email caoehong@I26.com

Mi Tian

Department of Respiratory Medicine, The Affiliated Drum Tower Hospital of Nanjing University Medical School, 32I Zhongshan Road, Nanjing, 210008, jiangsu, People's Republic of China

Email amy_tianI21@I26.com
Background: Campylobacter rectus is one of the anaerobic bacteria in the mouth. Case Presentation: We report the case of a 73-year-old man admitted for lung abscess caused by Campylobacter rectus with unique manifestations under electronic bronchoscopy, and the pathogen is first reported to be confirmed by metagenomic next-generation sequencing (mNGS) through testing bronchoalveolar lavage fluid.

Conclusion: Sometimes, Campylobacter rectus can cause infection outside the mouth such as lung abscess. Most patients have good outcomes.

Keywords: Campylobacter rectus, Wolinella recta, lung abscess, metagenomic nextgeneration sequencing, mNGS, electronic bronchoscopy

\section{Background}

Campylobacter rectus is one of the anaerobic bacteria in the mouth, which was previously known as Wolinella recta. ${ }^{1}$ It was identified as a common pathogen closely related to human periodontal disease in $1979 .{ }^{2}$ In 1984 , the first case of Campylobacter rectus infection outside the oral was reported. ${ }^{3}$ Then, it was reassigned to the genus Campylobacter in $1991 .^{4}$

\section{Case Report}

A 73-year-old man with a history of chronic obstructive pulmonary disease (COPD) for more than 10 years, he regularly inhaled salmeterol/fluticasone propionate $(50 \mu \mathrm{g} / 500 \mu \mathrm{g})$ twice a day. He had 30 pack-years of smoking history and quit smoking for more than 10 years. He was a farmer by profession. He was admitted to hospital with cough and hemoptysis for more than five months.

Admission blood tests showed a white cell count of $5.8 \times 10^{9} / \mathrm{L}$, C-reactive protein $3.1 \mathrm{mg} / \mathrm{L}$ and interleukin-6 $16.32 \mathrm{pg} / \mathrm{mL}$. All of sputum smear acid-fast staining, tuberculin test and tuberculosis antibody test were negative. Serum biomarkers of lung cancer, such as carcinoembryonic antigen (CEA), Cytokeratin-19fragment (CYFRA21-1), squamous cell carcinoma antigen (SCC), and neuronspecific enolase (NSE) were negative.

The images of computed tomography (CT) scan of the chest revealed large dense shadows and cavity formation in the inferior lobe of the left lung (Figure 1A). The electronic bronchoscopy showed a big and white neoplasm in the lower left lung, with a narrow opening and a lot of white necrotic material in the subsegment (Figure 2). Biopsy revealed chronic inflammation of endobronchial membrane with lymphoid follicular hyperplasia, but without any definite tumor cells (Figure 3). Acid-fast staining 

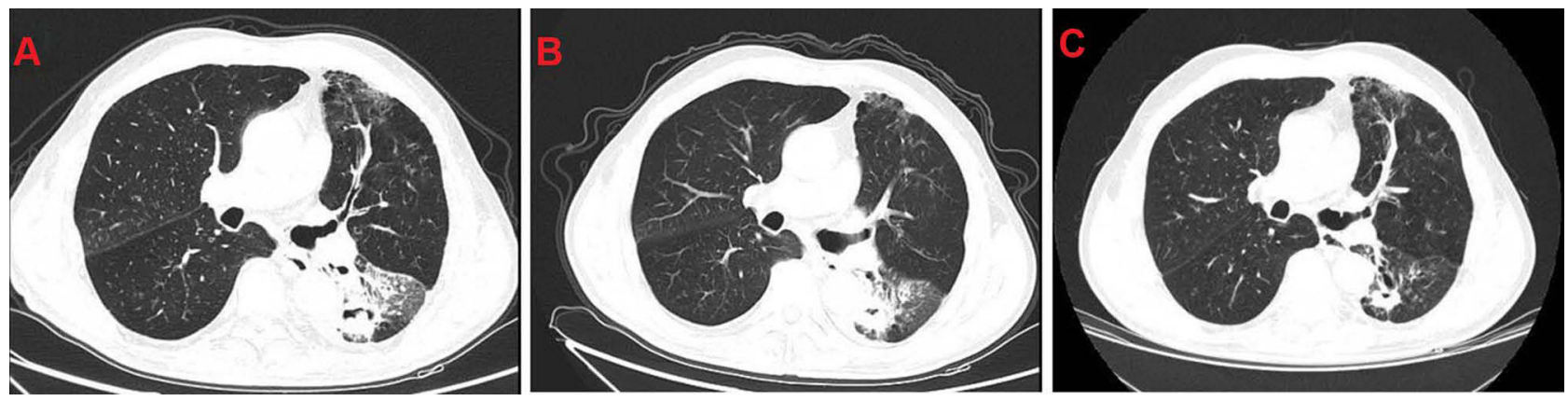

Figure I (A) CT revealed large dense shadows and cavity formation in the inferior lobe of the left lung. (B) The results of CT re-examination suggested that, the area of infection in the inferior lobe of the left lung was significantly reduced and the cavity was smaller. (C) The condition of the lung was further improved than before.
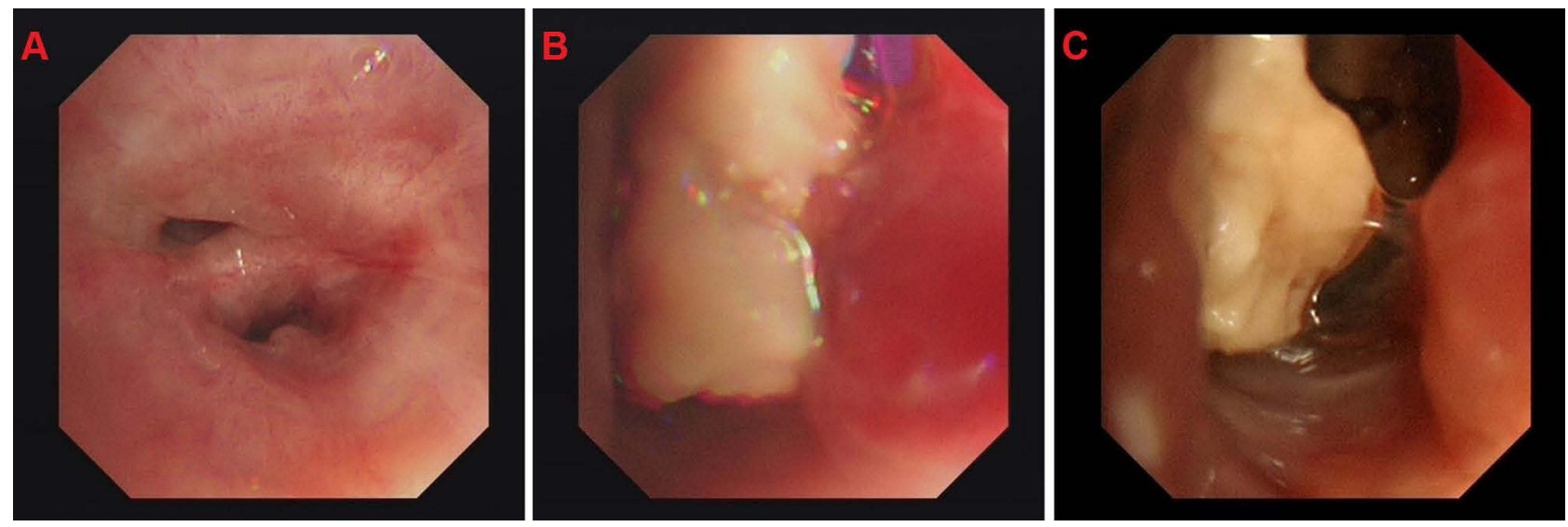

Figure 2 (A) The opening of the left lower lobe is narrow. (B and C) There is a big and white neoplasm in the lower left lung, with a lot of white necrotic material in the subsegment.

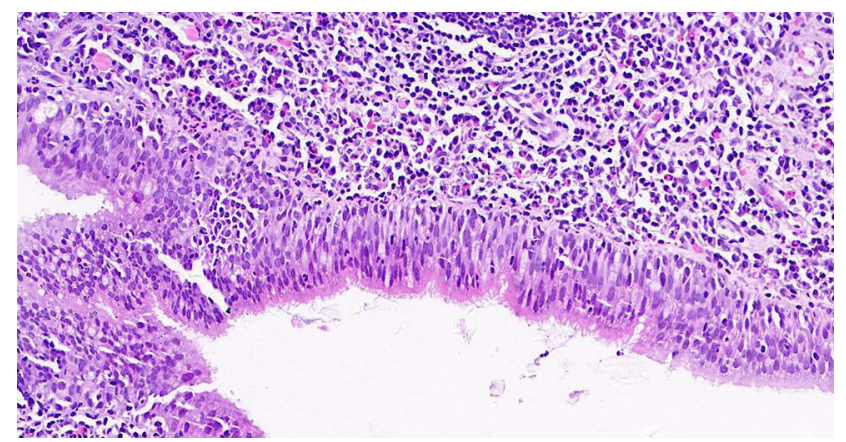

Figure 3 Biopsy revealed chronic inflammation of bronchial mucosa with lymphoid follicular hyperplasia, but no definite tumor cells (400X).

and Periodic Acid-Schiff (PAS) staining were both negative. Not only the traditional culture (including aerobic and anaerobic) but also the galactomannan (GM) test of bronchoalveolar lavage fluid were negative. Surprisingly, the mNGS of bronchoalveolar lavage fluid revealed 4415 sequences of Campylobacter rectus and 1091 sequences of Parvimonas micra.
Empirical antimicrobial therapy commenced immediately with intravenous tazobactam/piperacillin $(4.5 \mathrm{~g}$ three times daily) and ornidazole (500 $\mathrm{mg}$ twice daily) from the first day in the hospital. One week later when we got the result of mNGS, etimicin (300mg one time daily) was used in combination to enhance treatment against Gramnegative bacteria. Another two weeks later, the symptom of diarrhea in the patient was considered to be due to the imbalance of intestinal flora induced by long-term extensive use of broad-spectrum antibiotics. Therefore, the anti-infective treatment regimen was reduced to etimicin only. The patient was hospitalized for one month. The results of CT re-examination suggested that the area of infection in the inferior lobe of the left lung was significantly reduced, and the cavity was smaller (Figure 1B). After he was discharged from hospital, he was treated with oral levofloxacin ( $0.5 \mathrm{~g}$ once daily) for four months. The condition of the lung was further improved than before (Figure 1C). 


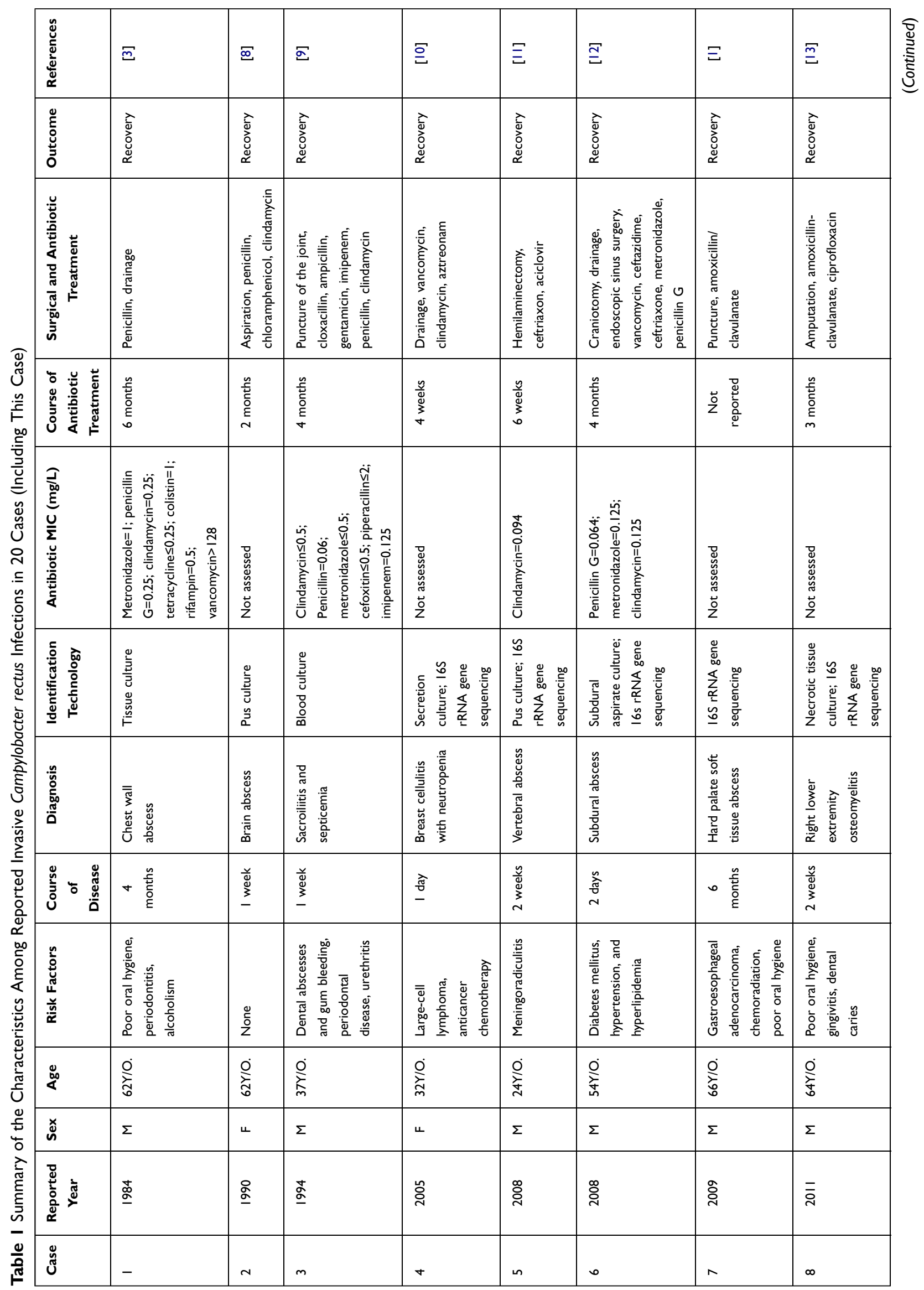




\begin{tabular}{|c|c|c|c|c|c|c|c|c|}
\hline 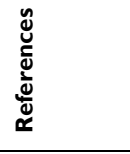 & $\underline{\underline{m}}$ & $\underline{\underline{m}}$ & F & $\underline{\underline{n}}$ & $\stackrel{\sigma}{\underline{\sigma}}$ & $\Xi$ & $\underline{\underline{\infty}}$ & $\Phi$ \\
\hline 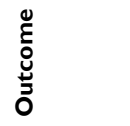 & 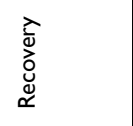 & $\begin{array}{l}\text { 㔛 } \\
\text { 口̃ }\end{array}$ & 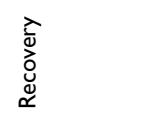 & 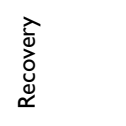 & 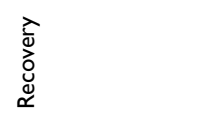 & $\begin{array}{l}\hat{\bar{v}} \\
\stackrel{\bar{U}}{\mathscr{U}} \\
\propto\end{array}$ & 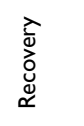 & $\begin{array}{l}\text { 哥 } \\
\text { 口̆ }\end{array}$ \\
\hline 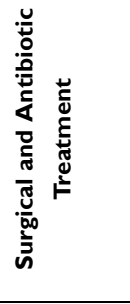 & 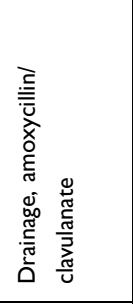 & 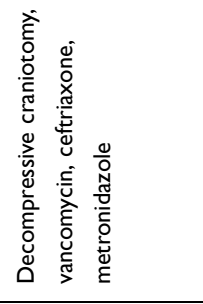 & 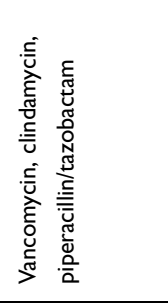 & 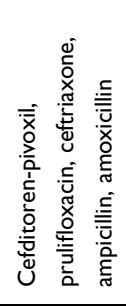 & 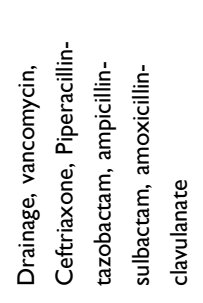 & 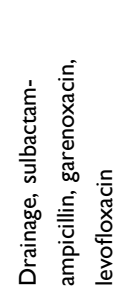 & 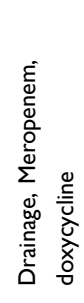 & 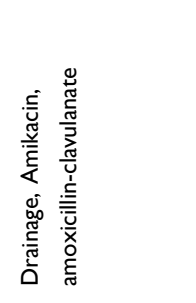 \\
\hline 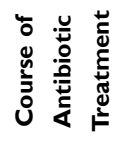 & 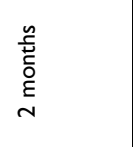 & 1 & 1 & $\begin{array}{l}\text { 薃 } \\
\stackrel{n}{n}\end{array}$ & $\begin{array}{l}\tilde{y} \\
\stackrel{\tilde{w}}{0} \\
3 \\
0\end{array}$ & 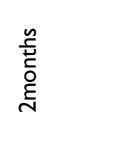 & 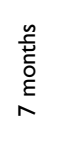 & 1 \\
\hline 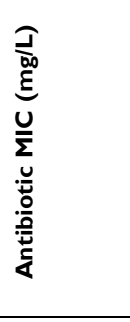 & 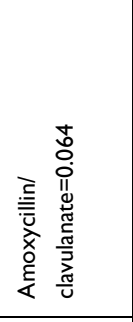 & 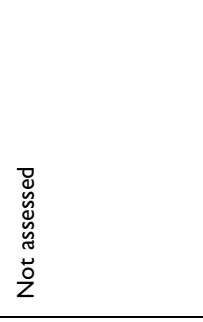 & 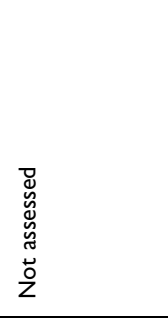 & 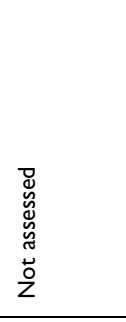 & 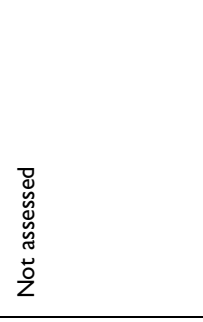 & 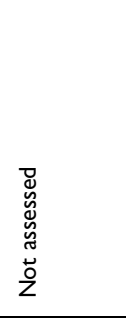 & 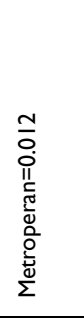 & 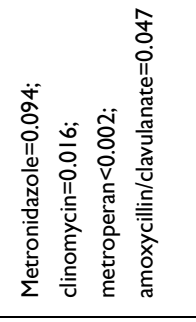 \\
\hline 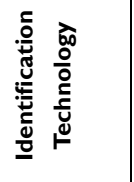 & 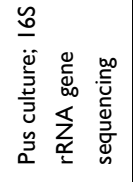 & 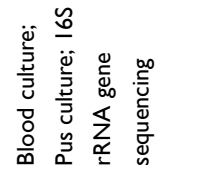 & 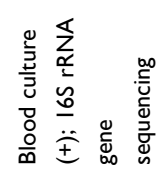 & 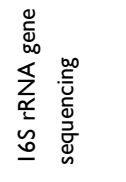 & 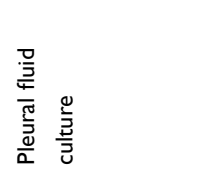 & 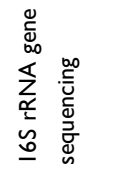 & $\begin{array}{l}\frac{\omega}{0} \\
\frac{1}{0} \\
\frac{1}{\Sigma} \\
\Sigma \\
\Sigma\end{array}$ & 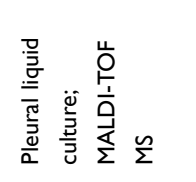 \\
\hline 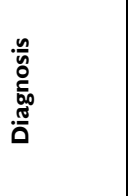 & 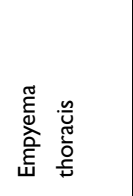 & 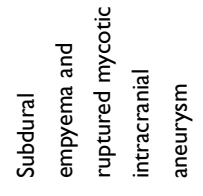 & 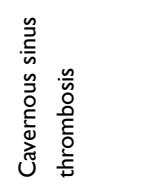 & 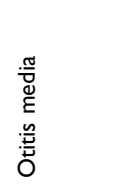 & 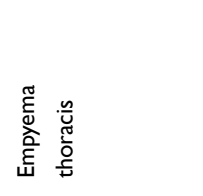 & 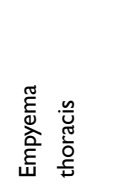 & 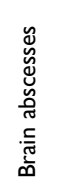 & 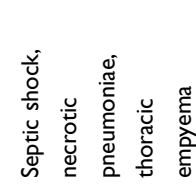 \\
\hline 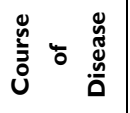 & 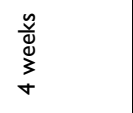 & $\begin{array}{l}\frac{\tilde{y}}{\Phi} \\
\stackrel{\varpi}{3} \\
\sim\end{array}$ & 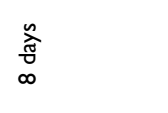 & $\begin{array}{l}\underline{n} \\
\stackrel{\tilde{f}}{0} \\
\underline{m}\end{array}$ & 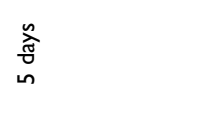 & 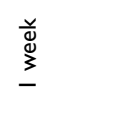 & $\begin{array}{l}\frac{y}{\tilde{y}} \\
\sum_{\infty}^{\underline{3}} \\
\infty\end{array}$ & $\begin{array}{l}\stackrel{\text { ळ}}{\grave{\Xi}} \\
\underline{3}\end{array}$ \\
\hline 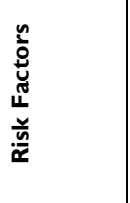 & 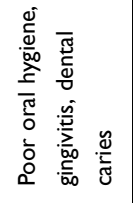 & $\begin{array}{l}\stackrel{0}{0} \\
\text { ¿ }\end{array}$ & 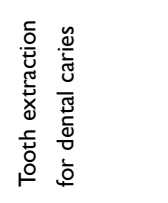 & 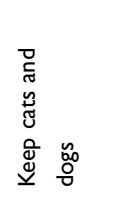 & 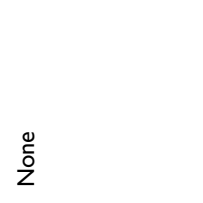 & 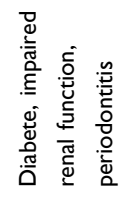 & 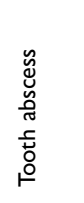 & 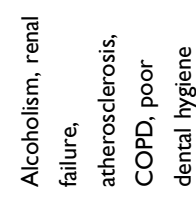 \\
\hline 品 & ○ & $\frac{\rho}{\frac{\partial}{\gamma}}$ & $\stackrel{\circ}{\stackrel{0}{亡}}$ & $\stackrel{0}{\circ}$ & 을 & $\stackrel{0}{\stackrel{2}{n}}$ & $\frac{\dot{0}}{i}$ & $\frac{0}{2}$ \\
\hline$\stackrel{\times}{凶}$ & $\Sigma$ & 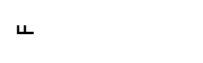 & $\Sigma$ & $\Sigma$ & ч & $\Sigma$ & $\Sigma$ & $\Sigma$ \\
\hline 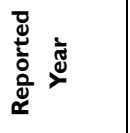 & $\overline{\bar{\alpha}}$ & $\overline{\bar{\alpha}}$ & $\stackrel{+}{\stackrel{*}{d}}$ & $\stackrel{\circ}{\circ}$ & $\stackrel{\circ}{\circ}$ & $\stackrel{\circ}{\circ}$ & $\hat{\bar{\alpha}}$ & $\hat{\bar{\alpha}}$ \\
\hline 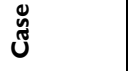 & $\sigma$ & 으 & $=$ & $\simeq$ & $\underline{m}$ & \pm & $\underline{\underline{n}}$ & $\underline{\bullet}$ \\
\hline
\end{tabular}




\begin{tabular}{|c|c|c|c|}
\hline ¿্d & $\overline{\bar{\Sigma}}$ & $\bar{\Xi}$ & 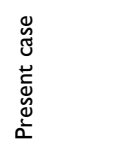 \\
\hline 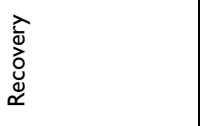 & 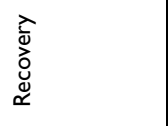 & 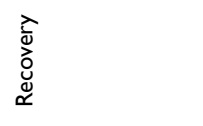 & 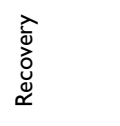 \\
\hline 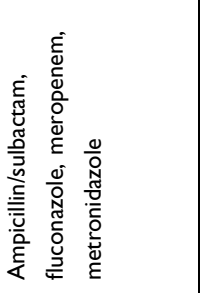 & 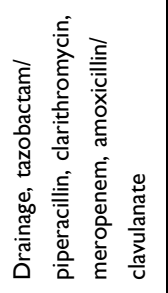 & 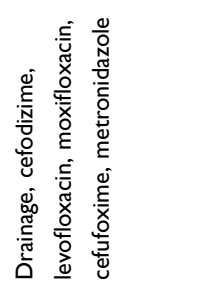 & 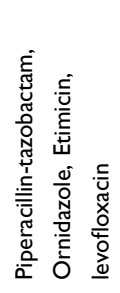 \\
\hline $\begin{array}{l}\text { 㖇 } \\
\text { స }\end{array}$ & 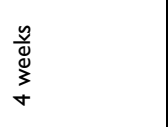 & 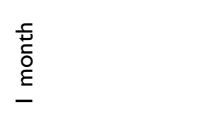 & 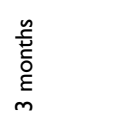 \\
\hline 1 & 1 & 1 & 1 \\
\hline 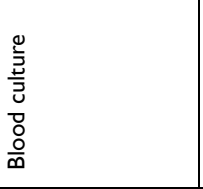 & 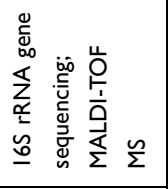 & 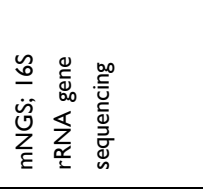 & $\overbrace{\underline{E}}^{\tilde{U}}$ \\
\hline 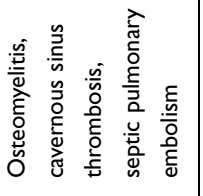 & 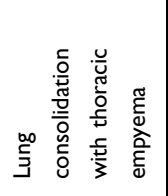 & 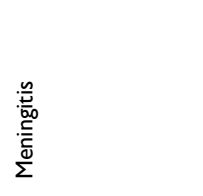 & 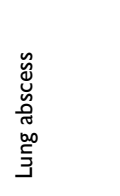 \\
\hline 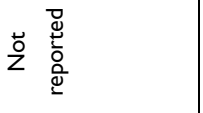 & 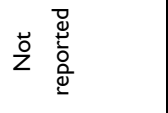 & n $\frac{\underline{n}}{\underline{\underline{E}}}$ & $\begin{array}{l}\text { 䇏 } \\
\stackrel{\overline{0}}{\mathrm{E}} \\
\underline{-}\end{array}$ \\
\hline 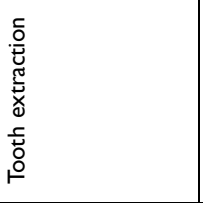 & 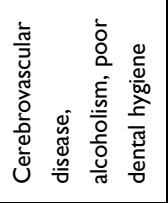 & 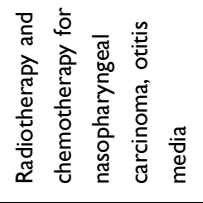 & 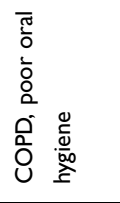 \\
\hline$\frac{\circ}{\grave{2}}$ & 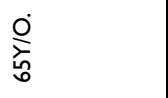 & $\frac{0}{\stackrel{8}{8}}$ & 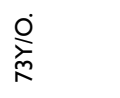 \\
\hline$\Perp$ & $\Sigma$ & $\Sigma$ & $\Sigma$ \\
\hline 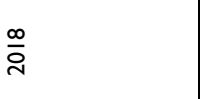 & $\stackrel{\circ}{\bar{\nu}}$ & $\overline{\bar{N}}$ & ڤ్రి \\
\hline$\Sigma$ & $\underline{\infty}$ & $\underline{a}$ & ని \\
\hline
\end{tabular}




\section{Discussion}

Campylobacter rectus is Gram-negative, with no spores and can be cultured in microaerobic or anaerobic state. Its colonies are translucent, rough, flat and non-hemolytic. The morphology of Campylobacter rectus is straight rod-shaped, arcuate or $\mathrm{S}$ shape. Urease and oxidase tests are both negative.

Campylobacter rectus is one of the oral colonization flora. In 2007, a large study involving 1294 healthy adults in southern Finland found that $31.3 \%$ of them had been detected Campylobacter rectus in the saliva. ${ }^{2}$ Sometimes it can cause infections outside the mouth, but the reasons are not completely clear. The table summarizes the data of 20 cases (including this case) searched from the literatures (Table 1). The age of the patients ranged from 10 months to 75-year-old. Most of the patients ranged from 50 to 70 years old (12/20), among which 55\% patients $(11 / 20)$ had dental caries, periodontitis, poor oral hygiene and other oral risk factors, and $15 \%(3 / 20)$ had a history of malignant tumor. The site of infection is varied, including empyema, brain abscess, osteomyelitis, etc. In terms of prognosis, only two patients died unfortunately, while the remaining patients $(18 / 20)$ were discharged after effective anti-infection treatment, puncture or incisional drainage, and the success rate of the comprehensive treatment was $90 \%$. Pathogens can be identified in a variety of ways, including traditional culture, $16 \mathrm{~S}$ rRNA gene sequencing, matrix-assisted laser desorption/hours-of-flight mass spectrometry, and mNGS. The duration of anti-infective therapy for Campylobacter rectus varied from 23 days to 6 months, except for 2 deaths.

Electronic bronchoscopy, as a routine technique for respiratory infections, plays an important role in the diagnosis and treatment of respiratory diseases. This technique can detect early abnormalities in the lumen that might not be found by CT scanning. At the same time, samples can be taken for corresponding tests. In this case, a large amount of white necrotic material was found in the bronchial lumen at the lesion site, blocking the lumen and attaching to the wall. This is the first reported case of lung abscess caused by Campylobacter rectus under the electronic bronchoscope.

There are few literatures on the anti-infection treatment of Campylobacter rectus. In 2002, a study in Italian about periodontal anaerobe which can cause systemic infection found that Campylobacter rectus is sensitive to a variety of antibiotics except moxifloxacin, ${ }^{5}$ such as penicillin, amoxycillin/clavulanate, cefoxitin, etc. In 2007, another study in
Italian about anti-microbial susceptibility of oral microorganisms also confirmed that Campylobacter rectus was sensitive to multiple antibiotics, and none of the seven groups of samples produced $\beta$-lactamase. ${ }^{6}$ As a study on the antimicrobial resistance of this bacterium in 2020 , Rams et al from the Netherlands studied the in vitro resistance of periodontal pathogens to four antibiotics, and found no resistance to Campylobacter rectus. ${ }^{7}$

\section{Conclusion}

Campylobacter rectus is an oral colonizing bacterium which can cause infection outside the mouth. Most patients have a good outcome. In this case, a characteristic pattern of white necrotic material forms in the bronchial lumen. Metagenomic next-generation sequencing is one of the rapid diagnostic methods.

\section{Data Sharing Statement}

All raw data in the manuscript has been uploaded to the submission system.

\section{Ethics Approval and Consent to Participate}

The study has been approved by the Independent Ethics Committee of Nanjing Tongren Hospital (Approval No: TRLLKY2020013.1). We obtained the patient's consent and signed the informed consent.

\section{Consent for Publication}

The manuscript is approved by all authors for publication.

\section{Patient Consent}

The patient provided written informed consent for the case details and accompanying images to be published.

\section{Author Contributions}

All authors made a significant contribution to the work reported, whether that is in the conception, study design, execution, acquisition of data, analysis and interpretation, or in all these areas; took part in drafting, revising or critically reviewing the article; gave final approval of the version to be published; have agreed on the journal to which the article has been submitted; and agree to be accountable for all aspects of the work.

\section{Funding}

This work has not received any funding. 


\section{Disclosure}

No conflict of interest exists in the submission of this manuscript, and it is approved by all authors for publication.

\section{References}

1. Mahlen SD, Clarridge JE. Oral abscess caused by Campylobacter rectus: case report and literature review. J Clin Microbiol. 2009;47 (3):848-851. doi:10.1128/JCM.01590-08

2. Tanner AC, Haffer C, Bratthall GT, Visconti RA, Socransky SS. A study of the bacteria associated with advancing periodontitis in man. J Clin Periodontal. 1979;6:278-307. doi:10.1111/j.1600051X.1979.tb01931.x

3. Spiegel CA, Telford G. Isolation of Wolinella recta and Actinomyces viscosus from an actinomycotic chest wall mass. $J$ Clin Microbiol. 1984;20(6):1187-1189. doi:10.1128/jcm.20.6.1187-1189.1984

4. Vandamme P, Falsen E, Rossau R, et al. Revision of Campylobacter, Helicobacter, and Wolinella taxonomy: emendation of generic descriptions and proposal of Arcobacter gen.nov. Int $J$ Syst Bacteriol. 1991;41:88-103. doi:10.1099/00207713-41-1-88

5. Milazzo I, Blandino G, Musumeci R, Nicoletti G, Lo Bue AM, Speciale A. Antibacterial activity of moxifloxacin against periodontal anaerobic pathogens involved in systemic infections. Int $J$ Antimicrob Agents. 2002;20(6):451-456. doi:10.1016/S0924-8579(02)00190-5

6. Blandino G, Milazzo I, Fazio D, et al. Antimicrobial susceptibility and beta-lactamase production of anaerobic and aerobic bacteria isolated from pus specimens from orofacial infections. J Chemother. 2007;19(5):495-499. doi:10.1179/joc.2007.19.5.495

7. Rams TE, Sautter JD, van Winkelhoff AJ. Comparative in vitro resistance of human periodontal bacterial pathogens to tinidazole and four other antibiotics. Antibiotics (Basel). 2020;9(2):68. doi:10.3390/antibiotics9020068

8. Marrie TJ, Kerr E. Brain abscess due to Wolinella recta and Streptococcus intermedius. Can J Infect Dis. 1990;1(1):31-34.

9. Harvey P, Bayardelle P, Bélanger R, Fortin L. Sacroiliitis and septicemia caused by Campylobacter rectus and actinomyces odontolyticus. Can J Infect Dis. 1994;5(3):133-136.

10. Han XY, Tarrand JJ, Rice DC. Oral Campylobacter species involved in extraoral abscess: a report of three cases. J Clin Microbiol. 2005;43(5):2513-2515. doi:10.1128/JCM.43.5.2513-2515.2005

11. de Vries JJ, Arents NL, Manson WL. Campylobacter species isolated from extra-oro-intestinal abscesses: a report of four cases and literature review. Eur J Clin Microbiol Infect Dis. 2008;27(11):1119-1123. doi:10.1007/s10096-008-0550-2
12. Walters HL, Perloff S, Jungkind D, et al. A Campylobacter rectus subdural empyema. Infect Dis Clin Pract. 2008;16(5):332-334. doi:10.1097/IPC.0b013e3181654360

13. Lam JY, Wu AK, Ngai DC, et al. Three cases of severe invasive infections caused by Campylobacter rectus and first report of fatal C. rectus infection. J Clin Microbiol. 2011;49(4):1687-1691. doi:10.1128/JCM.02487-10

14. Leo QJ, Bolger DT Jr. Septic cavernous sinus thrombosis due to Campylobacter rectus infection. BMJ Case Rep. 2014;2014: bcr2013203351. doi:10.1136/bcr-2013-203351

15. Kakuta R, Hidaka H, Yano H, et al. First report of severe acute otitis media caused by Campylobacter rectus and review of the literature. $J \quad$ Infect Chemother. 2016;22(12):800-803. doi:10.1016/j. jiac.2016.06.001

16. Chen NY, Bender JM, Bard JD, Trost MJ, Corden MH. Something doesn't smell right: when a patient with empyema isn't responding to guideline-based management. Hosp Pediatr. 2016;6(11):702-706. doi:10.1542/hpeds.2015-0274

17. Ogata T, Urata T, Nemoto D, Hitomi S. Thoracic empyema caused by Campylobacter rectus. J Infect Chemother. 2017;23(3):185-188. doi:10.1016/j.jiac.2016.08.013

18. Martiny D, Dauby N, Konopnicki D, et al. MALDI-TOF MS contribution to the diagnosis of Campylobacter rectus multiple skull base and brain abscesses. New Microbes New Infect. 2017;19:83-86. doi:10.1016/j.nmni.2017.05.014

19. Noël A, Verroken A, Belkhir L, Rodriguez-Villalobos H. Fatal thoracic empyema involving Campylobacter rectus: a case report. Anaerobe. 2018;49:95-98. doi:10.1016/j.anaerobe.2017.12.014

20. Oka K, Nakano Y, Sazumi Y, et al. Clival osteomyelitis with cavernous sinus thrombosis due to Fusobacterium nucleatum and Campylobacter rectus induced by tooth extraction. Intern Med. 2018;57(22):3325-3328. doi:10.2169/internalmedicine.1025-18

21. Gray RM, Vidwans M. Mixed anaerobic thoracic empyema: the first report of Filifactor alocis causing extra-oral disease. New Microbes New Infect. 2019;29:100528. doi:10.1016/j.nmni.2019.100528

22. Qiu X, Wang J, Huang Y, Chen H. One case report of meningitis potentially caused by Fusobacterium nucleatum and Campylobacter rectus. Chin J Infect Chemother. 2019;19(3):315-318.
Infection and Drug Resistance

\section{Publish your work in this journal}

Infection and Drug Resistance is an international, peer-reviewed openaccess journal that focuses on the optimal treatment of infection (bacterial, fungal and viral) and the development and institution of preventive strategies to minimize the development and spread of resistance. The journal is specifically concerned with the epidemiology of antibiotic resistance and the mechanisms of resistance development and diffusion in both hospitals and the community. The manuscript management system is completely online and includes a very quick and fair peerreview system, which is all easy to use. Visit http://www.dovepress.com/ testimonials.php to read real quotes from published authors. 